\title{
BMJ Open Clinical cardiovascular risk during young adulthood in offspring of hypertensive pregnancies: insights from a 20-year prospective follow-up birth cohort
}

\author{
Esther F Davis, ${ }^{1}$ Adam J Lewandowski, ${ }^{1}$ Christina Aye, ${ }^{1,2}$ Wilby Williamson, ${ }^{1}$ \\ Henry Boardman, ${ }^{1}$ Rae-Chi Huang, ${ }^{3}$ Trevor A Mori, ${ }^{4}$ John Newnham, ${ }^{5}$ \\ Lawrence J Beilin, ${ }^{4}$ Paul Leeson ${ }^{1}$
}

To cite: Davis EF, Lewandowski AJ, Aye C, et al. Clinical cardiovascular risk during young adulthood in offspring of hypertensive pregnancies: insights from a 20-year prospective follow-up birth cohort. BMJ Open 2015;5:e008136. doi:10.1136/ bmjopen-2015-008136

- Prepublication history and additional material is available. To view please visit the journal (http://dx.doi.org/ 10.1136/bmjopen-2015008136).

Received 11 March 2015 Accepted 14 April 2015

CrossMark

\begin{abstract}
${ }^{1}$ Oxford Cardiovascular Clinical Research Facility, Division of Cardiovascular Medicine, Radcliffe Department of Medicine, Oxford, UK

${ }^{2}$ Nuffield Department of Obstetrics and Gynaecology, University of Oxford, Oxford, UK

${ }^{3}$ Telethon Kids Institute, Crawley, Western Australia, Australia

${ }^{4}$ School of Medicine and Pharmacology, Crawley, Western Australia, Australia

${ }^{5}$ School of Women's and Infants' Health, University of Western Australia, Crawley, Western Australia, Australia
\end{abstract}

Correspondence to Professor Paul Leeson; paul.leeson@cardiov.ox.ac.uk

\section{ABSTRACT}

Objectives: Offspring of hypertensive pregnancies have increased cardiovascular risk factors during childhood. We hypothesised that offspring of hypertensive pregnancies would demonstrate increased clinical levels of hypertension by young adult life, which would be proportional to the severity of the pregnancy complication.

Design: Prospective birth cohort study

Setting: Tertiary obstetric hospital.

Participants: 2868 young adult offspring of women enrolled during pregnancy into the Western Australia Pregnancy Cohort (Raine) Study.

Main outcome measures: Cardiovascular risk, including incidence of hypertension and metabolic disease, in those born to hypertensive compared to normotensive pregnancies.

Results: Young adult offspring of hypertensive pregnancies were 2.5 times $(95 \% \mathrm{Cl} 1.32$ to 4.56 , $\mathrm{p}=0.004$ ) more likely to have global lifetime risk (QRISK) scores above the 75th centile. Thirty per cent of 20 year olds with hypertensive blood pressures were born following a hypertensive pregnancy. Preeclampsia or hypertension resulting in preterm birth associated with a threefold ( $95 \% \mathrm{Cl} 1.3$ to $7.0, \mathrm{p}=0.01$ ) greater risk of being hypertensive by age 20 years, with no differences in body mass index. Whereas pregnancy-induced hypertension associated with a smaller $3 \pm 1 \mathrm{~mm} \mathrm{Hg}$ blood pressure rise $(p=0.001)$ and a twofold $(95 \% \mathrm{Cl} 1.5$ to $2.8, p=0.001)$ greater risk of being obese or overweight. Risk factor associations were consistent throughout early life and independent of other birth-factors.

Conclusions: Incidence of offspring hypertension was significantly increased in those whose mothers had a more complicated pregnancy history, including preterm birth and pre-eclampsia.

\section{INTRODUCTION}

Adults born to a hypertensive pregnancy have a twofold increased risk of stroke. ${ }^{1}$

\section{Strengths and limitations of this study}

- There have been no previously published prospective cohort studies addressing severity of pregnancy hypertension and clinical risk of hypertension in the offspring.

- This study provides comprehensive data collection on a large cohort of individuals over a 20-year period.

- Weaknesses include the observational nature of the study and loss to follow-up.

Hypertensive pregnancy disorders have been associated with altered blood pressure, body size and metabolic factors in the offspring during neonatal life, childhood and adolescence. ${ }^{2-8}$ However, effect sizes vary and are relatively small compared to apparent adult stroke risk. Several prospective birth cohorts established in the 1990s are now entering adolescence and adulthood. $^{9}{ }^{10}$ Recent reports indicate those born following hypertensive pregnancy continue to have a higher average blood pressure in adult life, independent of other birth-related factors. ${ }^{11}$ However, the risk that a young adult born following a hypertensive pregnancy has blood pressures that exceed thresholds for diagnosis of hypertension (HTN), and therefore may present for medical advice, has not been studied. Furthermore, the relative contribution of metabolic factors to the adult risk profile remains unclear, ${ }^{2}$ as does, whether other birth-related factors, in particular, the severity of the hypertensive episode can be used to better stratify the risk for an individual. $^{12}$

We hypothesised that offspring of hypertensive pregnancies would demonstrate increased clinical levels of HTN by young adult life, which would be proportional to 
the severity of the pregnancy complication. We therefore studied whether pregnancy HTN is associated with clinically apparent cardiovascular risk in the offspring when they reach early adulthood, using the 20-year prospective follow-up data from the Western Australian Pregnancy Cohort (Raine) Study and determined if they had developed a specific hypertensive risk profile that might allow targeted screening and prevention. We determined associations between hypertensive pregnancy disorders and levels of clinical cardiovascular risk in adulthood ${ }^{13}$ quantified as a global lifetime risk score $\left(\mathrm{QRISK}^{14}\right)$ and according to clinical guidelines for diagnosis of hypertension, obesity and metabolic disorders. Detailed maternity and childhood records allowed differentiation of risk profiles based on characteristics of the pregnancy hypertensive episode, such as the occurrence of preterm birth or proteinuria. In addition, we considered consistency of risk profile patterns at earlier points in life and determined the impact of other perinatal and later life factors on associations.

\section{METHODS}

\section{Study population}

The Western Australian Pregnancy Cohort (Raine) Study consists of 2900 women enrolled between May 1989 and November 1991, in a controlled trial of ultrasound frequency and pregnancy outcome at, or before, the 18th week of gestation from a tertiary level obstetric hospital in Perth, Western Australia. ${ }^{15}$ Of 2868 children born to 2804 mothers have been followed for assessment of growth, development, metabolic and cardiovascular health to 20 years of age ${ }^{16}$ (figure 1). Measurement approaches at each stage have been reported previously and relevant information is included in the online supplementary methods. ${ }^{13}{ }^{16-18}$ In addition to the recorded absolute levels of cardiovascular risk factors, we characterised individuals based on current clinical guidelines for hypertension ${ }^{19}$ overweight and obesity ${ }^{20}$ and according to a calculated global lifetime risk score. ${ }^{14}$ Criteria are detailed in the online supplementary methods.

\section{Exclusion criteria and missing data}

Participants were excluded from this analysis if classed as having congenital malformation at birth, if their mother had pre-pregnancy HTN or if maternal HTN status during pregnancy was not documented. Where data was not available at any follow-up point the individual was excluded for that analysis only. Numbers of offspring followed up at each age, and numbers included in this analysis are summarised in online supplementary table S1.

\section{Pregnancy HTN and risk at age $\mathbf{2 0}$ years}

To study clinical risk at age 20 years in offspring of mothers with pregnancy HTN, we divided them into those born to mothers who developed de novo onset

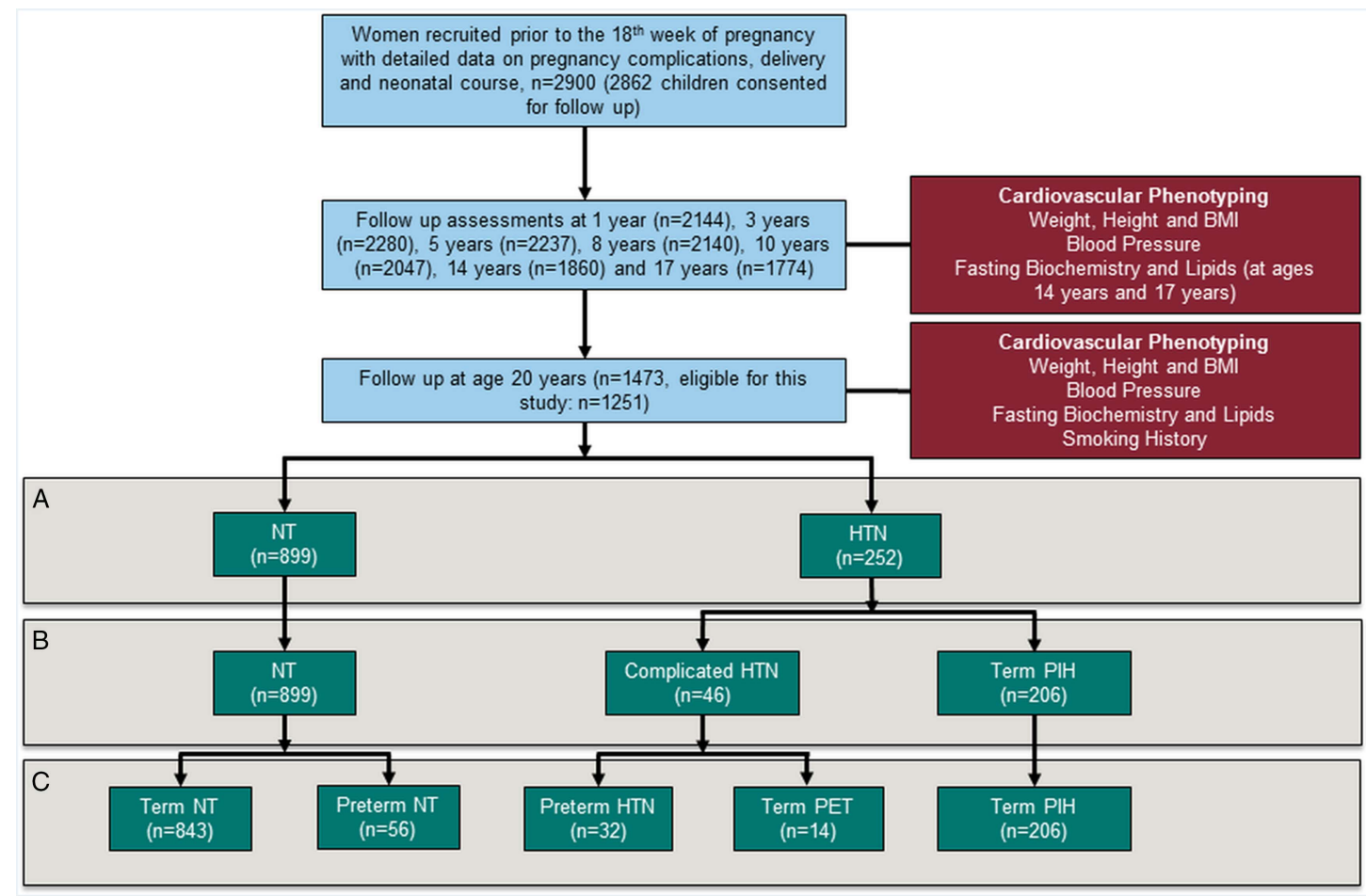

Figure 1 Flow diagram to demonstrate recruitment and follow-up of participants from birth to age 20 (blue boxes) with measurements performed (red boxes). Comparisons were performed between groups stratified by maternal pregnancy hypertension history. Initially, all those whose mother developed hypertension were compared to those with normotensive mothers $(A)$ and then pregnancy hypertension severity investigated $(B)$. Finally, impacts of other pregnancy-related factors linked to cardiovascular risk, in particular preterm birth $(\mathrm{C})$. 
HTN (>140/90 mm Hg) after the 20th week of pregnancy, consistent with ISSHP definitions for hypertensive pregnancy, ${ }^{21}$ and individuals born to a mother who remained normotensive (NT) based on data collected at time of pregnancy. We then performed a case-control comparison of differences in risk factor levels at age 20 years, as well as incidence of HTN and overweight or obesity.

\section{Maternal HTN severity}

We then studied whether severity of the pregnancy condition was relevant to risk profile. We divided the HTN group into two: pregnancy-induced hypertension (PIH) and complicated pregnancy hypertension (CompHTN). PIH encompassed all individuals born at term to a mother who developed HTN without proteinuria. CompHTN included all those whose mother had developed proteinuria $(>2+$ on dipstix or $300 \mathrm{mg}$ on $24 \mathrm{~h}$ urinary protein excretion; thus categorised as preeclampsia $^{21}$ ), or HTN sufficient to result in preterm delivery at less than 37 weeks gestation. Risk factors were compared between NT individuals and PIH, as well as with CompHTN. To determine the independent effect of preterm delivery we additionally compared associations within the separate groups (pre-eclampsia and HTN leading to preterm delivery) as well as between preterm and term NT pregnancies. No effects were evident so results are presented for the combined groups.

\section{Risk factors at other timepoints in life}

To determine whether differences in risk profile were consistent at other timepoints we compared absolute levels of blood pressure and body mass index (BMI) at each measurement timepoint between age 1 and 20 years. Groups were defined by maternal pregnancy HTN status.

\section{Associations between perinatal and later life risk factors and risk in adulthood}

Regression analyses were undertaken to study whether associations between cardiovascular risk and pregnancy HTN were independent of other potentially related factors. We studied associations between pregnancy categories and categorical clinical outcomes (HTN and obesity) based on forced entry logistic regression models. Model 1 was built on birth factors of potential relevance, specifically: sex, birth weight, gestational age, mode of delivery, maternal age, maternal BMI and maternal smoking during late pregnancy. Model 2 additionally added risk factors at age 20 specifically: smoking status, serum insulin levels, and cholesterol levels. For regression models of HTN, participant BMI was also added into model 2. Model 3 further incorporated a measure of socioeconomic status in adulthood (offspring average monthly income), average weekly alcohol consumption and contraceptive pill usage. ORs and associated 95\% CIs with $\mathrm{p}$ values are reported for each pregnancy category of interest.

\section{Statistical analysis}

All statistical analyses were carried out using SPSS V.22. Normality testing was undertaken by visual assessment of normality curves and the Shapiro-Wilk test prior to analysis. Triglycerides, insulin and glucose were log transformed. Comparison between groups for continuous variables was performed with a two-sided, independentsamples Student t test for normally distributed data. Measurements across multiple timepoints were compared using a repeat measurement analysis of variance, while single time point measures were compared with a two-sided, independent-samples Student $\mathrm{t}$ test with adjustment for birth-weight $\mathrm{z}$ score and participant sex. Categorical variables and categories of clinical risk were compared with a $\chi^{2}$ test and, where informative ORs (and associated 95\% CIs) were calculated by binary logistic regression for the odds of clinical outcome. p Values less than 0.05 were considered significant. Absolute values in each group are presented as the mean \pm SD. Mean differences between groups are presented as the mean \pm SEM.

\section{RESULTS}

\section{Population and perinatal characteristics}

From the 2868 individuals recruited at birth, 1473 were followed up at age 20 years and 1151 met eligibility criteria, of which 899 had NT mothers during pregnancy and 252 had a mother with a hypertensive pregnancy disorder (figure 1). Incidence of maternal pregnancy HTN in this follow-up cohort did not differ from the original cohort (see online supplementary table S2). However, rate of maternal smoking in pregnancy was slightly lower and the offspring had slightly higher birth weight with longer gestation, consistent with previous reports in this cohort related to less children from socially disadvantaged families remaining in the study beyond the third year. ${ }^{17}$

\section{Pregnancy HTN and risk at age 20 years}

Mean differences in cardiovascular risk factors are presented in table 1 and figure 2 with OR for diagnoses presented in figure 2. Those born following hypertensive pregnancy had on average a $3.7 \mathrm{~mm} \mathrm{Hg}$ higher systolic blood pressure at age 20 years $(p<0.001)$ and a $1.4 \mathrm{~mm} \mathrm{Hg}$ higher diastolic blood pressure $(\mathrm{p}<0.05)$. Thirty per cent of those with hypertensive blood pressure levels had a history of maternal pregnancy HTN $(22 / 74)$. BMI was $1.1 \mathrm{~kg} / \mathrm{m}^{2}$ higher, in the HTN group, which resulted in $42 \%$ being overweight or obese and a 1.8-fold increased risk of a BMI $>35 \mathrm{~kg} / \mathrm{m}^{2} \quad(\mathrm{p}<0.001)$. Apart from a $0.05 \mathrm{mmol} / \mathrm{L}$ lower high-density lipoprotein (HDL; $\mathrm{p}=0.04$ ), those born to HTN had no consistent differences in metabolic parameters at age 20 years (table 1). Changes in blood pressure and body size meant those born to HTN had a higher lifetime QRISK score at age 20 years $(27.8 \pm 6.2$ vs $26.5 \pm 5.8, \mathrm{p}=0.005)$ with 
Table 1 Characteristics at birth and age 20

\begin{tabular}{|c|c|c|c|c|}
\hline & $\begin{array}{l}\text { Normotensive } \\
\text { pregnancy } \\
\mathrm{N}=899\end{array}$ & $\begin{array}{l}\text { Hypertensive } \\
\text { pregnancy } \\
\mathrm{N}=252\end{array}$ & $\begin{array}{l}\mathrm{PIH} \\
\mathrm{N}=206\end{array}$ & $\begin{array}{l}\text { Complicated } \\
\text { hypertension } \\
n=46\end{array}$ \\
\hline \multicolumn{5}{|l|}{ Infant characteristics } \\
\hline Sex (\% male) & $49.7 \%(477)$ & $57.1 \%(145)^{*}$ & $59.2 \%(122)$ & $50 \%(23)$ \\
\hline Gestation (weeks) & $39.5(1.9)$ & $39.1(2.2)^{\star}$ & $39.7(1.4)$ & $36.1(2.7)^{\star} \dagger$ \\
\hline Birth weight $(g)$ & $3363(527)$ & $3282(616)$ & $3422(481)$ & $2658(760)^{*} \dagger$ \\
\hline Birth weight z-score & $-0.04(0.92)$ & $-0.03(0.98)$ & $-0.03(1.0)$ & $-0.06(1.01)$ \\
\hline Head circumference $(\mathrm{cm})$ & $34.5(1.7)$ & $34.4(1.9)$ & $34.8(1.6)$ & $32.8(2.5)^{\star} \dagger$ \\
\hline \multicolumn{5}{|l|}{ Maternal characteristics } \\
\hline Maternal age (years) & $29.4(5.7)$ & $29.1(5.8)$ & $29.0(5.3)$ & $29.8(5.9)$ \\
\hline Maternal BMI $\left(\mathrm{kg} / \mathrm{m}^{2}\right)$ & $21.73(3.77)$ & $23.07(4.11)^{\star}$ & $23.07(4.16)^{*}$ & $23.10(3.89)^{\star}$ \\
\hline Smoking in late pregnancy (\%) & $23.0 \%(207)$ & $19 \%(48)$ & $20.9 \%(43)$ & $10.9 \%(5)^{\star}$ \\
\hline Multiple pregnancies (\%) & $4 \%(36)$ & $5.4 \%(14)$ & $1 \%(2)$ & $26 \%(12)^{\star} \dagger$ \\
\hline Gestational diabetes (\%) & $1.4 \%(13)$ & $2.8(7)$ & $2.9 \%(6)$ & $2.2 \%(1)$ \\
\hline \multicolumn{5}{|l|}{ Cardiovascular risk factors age 20} \\
\hline BMI & $24.14(4.7)$ & $25.23(5.5)^{\star}$ & $25.3(5.5)^{\star}$ & $24.8(5.5)$ \\
\hline Systolic blood pressure & $116.3(13.0)$ & $120.0(12.8)^{\star}$ & $119.7(12.6)^{\star}$ & $121.8(14.0)^{*}$ \\
\hline Diastolic blood pressure & $64.9(8.0)$ & $66.3(12.8)^{\star}$ & $66.5(8.4)$ & $65.3(7.8)$ \\
\hline Smokers (\%) & $15.6 \%(130)$ & $14.0 \%(32)$ & $13.3 \%(24)$ & $16.3 \%(8)$ \\
\hline Metabolic factors & $\mathrm{n}=786$ & $n=223$ & $n=185$ & $\mathrm{n}=37$ \\
\hline Glucose (mmo/L) & $4.96(0.42)$ & $4.98(0.52)$ & $4.97(0.47)$ & $5.06(0.69)$ \\
\hline Insulin (pmol/L) & 4.63 (5.69) & $4.37(4.02)$ & $4.37(4.00)$ & $4.39(4.19)$ \\
\hline Total cholesterol (mmol/L) & $4.34(0.81)$ & $4.23(0.75)$ & $4.20(0.74)$ & $4.36(0.83)$ \\
\hline Triglycerides (mmol/L) & $1.09(0.80)$ & $1.09(0.60)$ & $1.08(0.59)$ & $1.12(0.65)$ \\
\hline HDL_cholesterol (mmol/L) & $1.34(0.32)$ & $1.29(0.32)^{\star}$ & $1.29(0.32)$ & $1.28(0.32)$ \\
\hline LDL_cholesterol (mmol/L) & $2.50(0.67)$ & $2.44(0.61)$ & $2.41(0.62)$ & $2.56(0.59)$ \\
\hline
\end{tabular}

a 2.5 fold increased chance of being above the $75 \%$ centile for lifetime risk (95\% CI 1.32-4.56 p=0.004).

\section{Severity of maternal HTN}

Absolute increase in lifetime QRISK score and risk of exceeding the $75 \%$ centile was similar in each hypertensive pregnancy group (CompHTN $10.8 \%$ vs PIH $7.9 \% \mathrm{p}=0.55)$. However, risk patterns differed between groups so that those whose mothers had complicated HTN had a $5.3 \pm 1.9 \mathrm{~mm} \mathrm{Hg} \quad(\mathrm{p}=0.007)$ higher systolic blood pressure compared to a $3.4 \pm 1 \mathrm{~mm} \mathrm{Hg}(\mathrm{p}=0.001)$ increase in those born following PIH (table 1 and figure 2). This difference resulted in individuals born to CompHTN being three times more likely to have hypertensive blood pressures $(\mathrm{p}=0.01)$, with no significant increase in those born following PIH (OR 1.29 (0.71-2.36) $\mathrm{p}=0.40)$. However, individuals born following $\mathrm{PIH}$ had more apparent changes in body size, with a $1.2 \pm 0.4 \mathrm{~kg} / \mathrm{m}^{2} \quad(\mathrm{p}=0.002)$ increase in BMI and a twofold increased risk of overweight or obesity $(\mathrm{p}<0.001)$ compared to those born to NT mothers. There were no significant effects on adiposity in those born following CompHTN $\left(0.6 \pm 0.90 \mathrm{~kg} / \mathrm{m}^{2}, \mathrm{p}=0.40\right)$. No differences in metabolic parameters were seen in either group.

\section{Associations at other timepoints in life}

At each measurement timepoint, from 1 year to young adult life, offspring of hypertensive pregnancy had higher blood pressure and BMI $(\mathrm{p}<0.05)$ but no differences in insulin, glucose or lipids when measured (see online supplementary table S3). Differences in systolic $\mathrm{BP}$ and BMI between hypertensive and NT groups were evident as early as 1 and 3 years respectively (figure 3) with the absolute difference in blood pressure remaining 2-3 mm Hg during childhood then increasing at age 17 and 20 years. Differences in body size were present from 3 years with an increase in difference with age.

\section{Associations between risk factors}

Those with a maternal HTN history had significant differences in several perinatal characteristics including higher incidence of special care unit admission and longer perinatal hospital stay. Differences were more pronounced in the CompHTN group (see online supplementary table S4). However, similar changes in risk factors were present in those born at term after preeclampsia and those born preterm due to maternal HTN (see online supplementary table S5). Furthermore, in this cohort, if the mother was NT, preterm birth was not associated with differences in risk factor levels at age 
QRISK Mean Difference

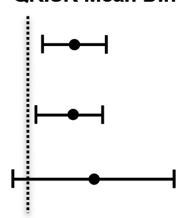

All HTN vs All NT

PIH vs All NT

Complicated HTN vs All NT
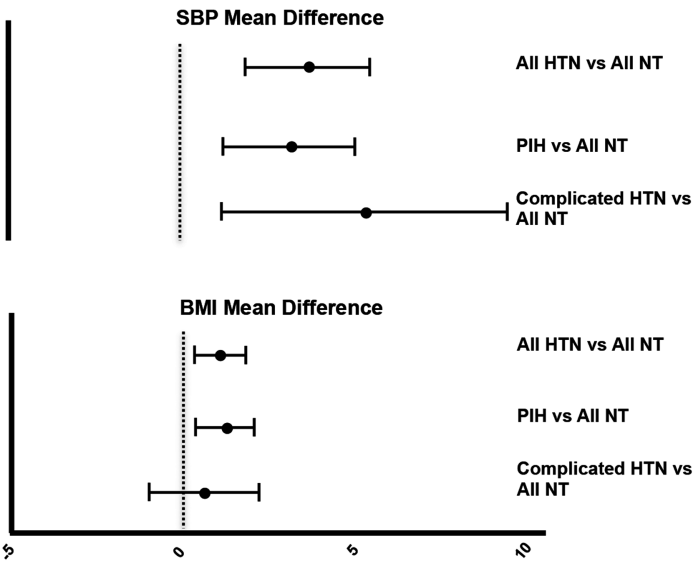

QRISK > 75 ${ }^{\text {th }}$ Centile Odds Ratio

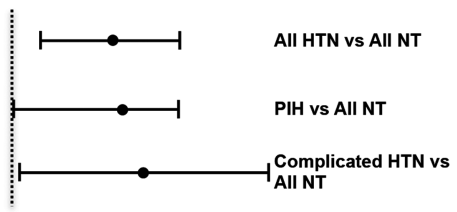

HTN Odds Ratio

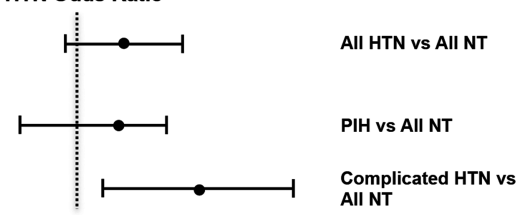

Overweight and Obese Odds Ratio

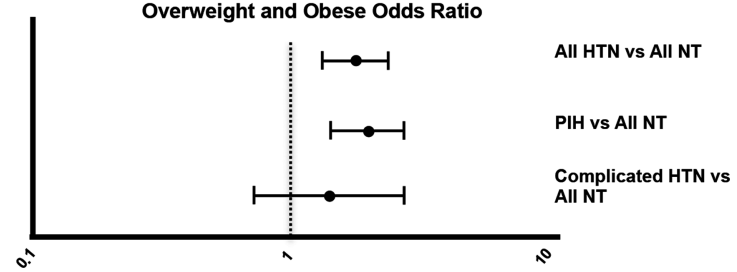

Figure 2 Mean difference (unadjusted values with $95 \% \mathrm{Cls}$ ) at age 20 for blood pressure, body mass index and lifetime QRisk score as well as ORs for clinically relevant elevation in these risk markers (lifetime QRisk $>75 \%$, blood pressure greater than $140 / 90 \mathrm{~mm} \mathrm{Hg}$ or BMl $>25 \mathrm{~kg} / \mathrm{m}^{2}$ ) in offspring of hypertensive mothers, as well as subjects grouped by severity of maternal hypertension into pregnancy-induced hypertension $(\mathrm{PIH})$ and complicated hypertension (pre-eclampsia or hypertension leading to preterm birth).

20 years compared to term born individuals. A lack of association with gestational age was also evident on bivariate analysis between perinatal factors and risk in adulthood (OR for risk of HTN/gestational week=1.0, $\mathrm{p}=0.95$ ).

Table 2 reports regression coefficients for associations between pregnancy hypertensive groups, blood pressure and body size. The association between maternal pregnancy HTN characteristics and offspring risk of HTN was not weakened by inclusion of maternal and perinatal factors in the model (model 1). Maternal pre-pregnancy body size was associated with increased blood pressure in young adulthood and mode of delivery and birth weight z-score related to BMI at age 20 years but, again,
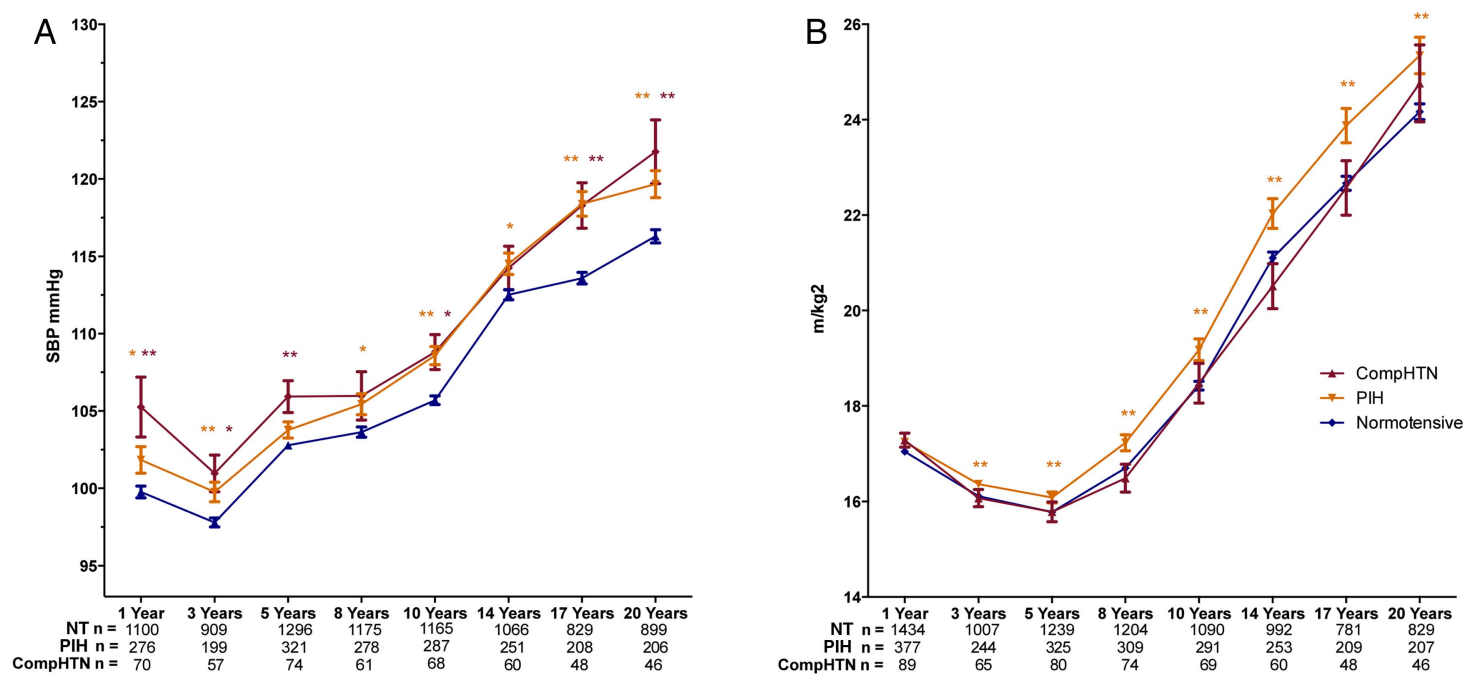

Figure 3 Trajectories of systolic blood pressure (A) and body mass index (BMI) (B) from 1 to 20 years of age in offspring of normotensive (blue), pregnancy-induced hypertension (PIH; orange) and complicated hypertensive (red) pregnancies. Offspring of PIH pregnancies have greater BMls at all stages, At all stages hypertensive pregnancy offspring have increased blood pressure compared to normotensive mothers with a similar difference in both groups. Data presented is mean $\pm \mathrm{SEM},{ }^{*}$ indicates $p<0.05$ and ${ }^{* *}$ indicates $p<0.01$. $p$ Values for difference of offspring of hypertensive pregnancies compared to the normotensive group adjusted for sex, gestation at delivery and birth weight. 
Table 2 Regression models for pregnancy hypertension groups and later risks of hypertension or overweight/obesity at age 20 years

\begin{tabular}{|c|c|c|c|c|c|c|c|}
\hline & \multicolumn{3}{|c|}{ Risk of hypertension } & & \multicolumn{3}{|c|}{ Risk of overweight or obese } \\
\hline & $\overline{\text { OR }}$ & $95 \% \mathrm{Cl}$ & p Value & & $\overline{\text { OR }}$ & $95 \% \mathrm{Cl}$ & p Value \\
\hline Bivariate association & & & & Bivariate association & & & \\
\hline PIH & 1.29 & 0.71 to 2.35 & 0.40 & $\mathrm{PIH}$ & 1.92 & 1.38 to 2.65 & $<0.001$ \\
\hline Complicated HTN & 2.98 & 1.27 to 7.02 & 0.01 & Complicated HTN & 1.44 & 0.73 to 2.83 & 0.29 \\
\hline Model 1 & & & & Model 1 & & & \\
\hline Complicated HTN & 6.25 & 1.96 to 19.96 & 0.002 & $\mathrm{PIH}$ & 1.68 & 1.18 to 2.39 & 0.004 \\
\hline Model 2 & & & & Model 2 & & & \\
\hline Complicated HTN & 6.74 & 1.25 to 36.29 & 0.03 & $\mathrm{PIH}$ & 1.62 & 1.05 to 2.52 & 0.03 \\
\hline Model 3 & & & & Model 3 & & & \\
\hline Complicated HTN & 6.63 & 1.17 to 37.57 & 0.03 & $\mathrm{PIH}$ & 1.59 & 1.02 to 2.48 & 0.04 \\
\hline
\end{tabular}

inclusion of these factors did not alter associations between hypertensive pregnancy groups and risk of HTN, overweight or obesity. Associations did not significantly vary in models 2 and 3, which incorporated later life risk factors. As no differences in glucose and lipid values were evident models were not developed for these risk characteristics.

\section{DISCUSSION}

This study has characterised, for the first time, clinically relevant levels of cardiovascular risk in young adults born to hypertensive pregnancies. They are 2.5 times more likely to have a lifetime QRISK score above the 75 th centile, which represents a $40 \%$ or greater chance of developing cardiovascular disease. ${ }^{14}$ Their systolic blood pressure was $3.7 \mathrm{~mm} \mathrm{Hg}$ higher and $30 \%$ of young adults with hypertensive blood pressures had been born following a pregnancy complicated by HTN. There was a graded association with severity of maternal pregnancy HTN so that more complicated pregnancy HTN associated with a threefold increased risk of HTN in the offspring by age 20 years. This variation was not explained by associated pregnancy complications such as prematurity. The increase in BMI associated with pregnancy HTN was more modest, at $1.1 \mathrm{~kg} / \mathrm{m}^{2}$, and was most apparent in those whose mother developed HTN late in pregnancy without features of pre-eclampsia.

Interestingly, no consistent changes in lipids or glucose tolerance were evident. We have previously published a systematic review investigating cardiovascular risk factors in children and young adults born to preeclamptic pregnancies, whereby we identified that young offspring of pregnancies complicated by pre-eclampsia already have increased blood pressure and BMI. ${ }^{2}$ This systematic review also identified acute metabolic changes at birth, with a paucity of reports in older offspring. Reports have now emerged that metabolic differences are not evident during childhood, ${ }^{4}{ }^{22}$ which accord with our current findings in adulthood. Nevertheless, offspring of hypertensive pregnancies still had a greater incidence of obesity and lower serum HDL-cholesterol levels. Increased BMI can develop without metabolic derangements; a phenotype still associated with significant cardiac and vascular changes. ${ }^{23}$ However, the discrepancy between absolute levels of metabolic factors and risk of obesity may relate to the high mean BMI in $\mathrm{NH}$ pregnancy offspring. As a result, the small absolute increase in BMI in the hypertensive pregnancy offspring was sufficient for a significant proportion to move above the overweight threshold without large changes in continuous metabolic risk markers. The impact of hypertensive pregnancy, independent of other birth-related factors, on blood pressure appears robust, clinically relevant and independent of body size differences. The $1.1 \mathrm{~kg} / \mathrm{m}^{2}$ greater BMI would only account for a $0.77 \mathrm{~mm} \mathrm{Hg}$ increase in systolic blood pressure ${ }^{24} \mathrm{com}-$ pared to the mean difference of $4 \mathrm{~mm} \mathrm{Hg}$ we observed.

Other studies have also reported that individuals born following hypertensive pregnancy continue to have a higher average blood pressure in adult life, independent of other birth-related factors. ${ }^{11}$ However, we have been able to identify that the difference in blood pressure is greater in those born following more severe pregnancy HTN. The group was defined directly from records of clinical measures, which provides significant strengths for analysis over studies that have relied on patient recall or historical diagnostic criteria. ${ }^{3}$ The observations are consistent with there being a graded association between severity of pregnancy HTN and offspring blood pressure. The more extreme complication of early onset preeclampsia, before 34 weeks gestation, has been associated with a $10 \mathrm{~mm} \mathrm{Hg}$ higher blood pressure in the mother up to 10 years after pregnancy. ${ }^{3} 25$ This condition was rare in the Raine cohort, ${ }^{21}$ but even in those offspring of later onset pre-eclampsia or whose mother had HTN sufficient to lead to later preterm delivery, one in five had developed hypertensive blood pressures by the age of 20 years. This compares to the more typical 1 in 17 of young adults born to NT pregnancy. ${ }^{26}$ 
Perinatal complications were higher in the complicated HTN group and offspring blood pressure is known to increase with prematurity. ${ }^{5}$ However, $30 \%$ of preterm births are linked with maternal HTN, ${ }^{27} 28$ and this could lead to collider stratification bias, whereby associations with later outcome are driven by causes of preterm birth rather than prematurity per se. ${ }^{29}$ Although very preterm birth is associated with both higher blood pressure and metabolic derangements, ${ }^{4} 5^{5} \quad 7^{30-32}$ those born very preterm following maternal HTN still have distinct vascular responses compared to those born to NT mothers. ${ }^{4}$ Unique biological pathways independent of gestation may therefore link pregnancy HTN with offspring blood pressure. This would explain why in the Raine cohort, in which $80 \%$ of preterm births were in later gestation, ${ }^{28}$ hypertensive pregnancy was the main predictor of later offspring blood pressure.

Shared genetics may explain why both mother and offspring exhibit increased cardiovascular risk after a hypertensive pregnancy. As heritability of pre-eclampsia is also $55 \%,{ }^{33}$ it is possible genetic variants in vascular developmental pathways could underlie both pregnancy complications and result in accelerated HTN development in the offspring. We have recently demonstrated that individuals born preterm and to hypertensive pregnancies demonstrate an enhanced circulating antiangiogenic blood profile, similar to that observed in women with pregnancy HTN, which is related to reductions in capillary density and elevations in blood pressure ${ }^{7}$ Therefore, inheritance of genetic variation that alters the angiogenic biological response of an individual could contribute to increases in risk for the offspring. Alternatively, as siblings of those born to pregnancies complicated by pre-eclampsia, who themselves were born to uncomplicated pregnancies, do not demonstrate vascular abnormalities, ${ }^{34}$ these differences may be programmed by adverse exposures during perinatal life. The greatest active programming of the epigenome occurs in the fetus $^{35}$ and placental DNA is more hypomethylated following early, compared to late, onset pre-eclampsia. ${ }^{36}$ This observation would be consistent with the greater risk of HTN in the group with more complicated hypertensive pregnancies.

Data on all individuals originally recruited were not available at 20 years of age, or at earlier follow-up. However, risk factor differences at age 20 years were replicated in the independent measurements in earlier life. Moreover analysis suggested that loss to follow-up resulted in differences in only a few of the key perinatal characteristics considered in this study. The research clinic measures of blood pressure may generate different effect sizes compared to ambulatory, home or medical clinic measures. ${ }^{37}$ However, their use ensured risk was characterised for all participants, whereas clinical records tend to under diagnose HTN in young adults who have lower engagement with medical services. ${ }^{38} 39$ The mothers who had hypertensive pregnancies are, themselves, four times more likely to have presented with HTN during the follow-up period. ${ }^{40}$ We did not have data on parental HTN or blood pressure available at the 20 year follow-up, but risk of HTN in young adults relates to a parental history of HTN. ${ }^{41}$ Whether this is stronger in those whose mother had severe HTN during pregnancy requires investigation as the impact of maternal hypertensive pregnancy on offspring risk could be mediated through either a unique familial predisposition or the in utero environment. These data are based on a population recruited from the sole tertiary obstetric centre in Western Australia, and thus it is not clear whether these data will be generalisable to other populations. Nevertheless, the inclusive nature of the Raine recruitment strategy suggests we can cautiously propose that these findings may be relevant to the offspring of pre-eclamptic pregnancies in other settings. Seventy per cent of young adults with HTN had no history of maternal HTN in pregnancy and, for this group, classical risk factors such as body size, insulin levels and sex, remain the best way of identifying those with an increased risk of HTN.

In summary, we found $30 \%$ of young adults with hypertensive blood pressures were born to pregnancies complicated by HTN. Those born to mothers with markers of more severe pregnancy HTN were up to three times more likely to have hypertensive level blood pressures compared to those whose mothers had $\mathrm{NH}$ pregnancies. Neither variation in body size proportional to gestational age, or degree of prematurity, accounted for the differences in risk factors we observed related to pregnancy HTN. Differences in body size were evident, although this was predominantly in those born at term following less severe pregnancy HTN. Clinically relevant variations in other metabolic risk markers were not present. This specific, elevated blood pressure profile, particularly in offspring of more complicated pregnancies, may represent a unique underlying biological predisposition to HTN. From a public health perspective, a specific, targetable variation in risk, from childhood onwards, in easily-identifiable individuals, raises the possibility of tailored intervention approaches to prevent adult HTN.

Acknowledgements The authors would like to acknowledge all of the Raine Study Participants and the Raine Study Management and Team for cohort co-ordination and data collection. Core management of the Raine Study is funded by The University of Western Australia (UWA); the Raine Medical Research Foundation; the Telethon Kid's Institute; the UWA Faculty of Medicine, Dentistry and Health Sciences; the Women and Infants Research Foundation, Curtin University and Edith Cowan University. The authors acknowledge the long-term funding contribution from the Australian National Health and Medical Research Council.

Contributors EFD, AJL, PL, LB, TM and JN conceptualised and designed this analysis. EFD, AJL and PL analysed and interpreted the data and were responsible for the writing of the report. PL is guarantor. $\mathrm{RH}, \mathrm{TM}$, JN and LB assisted with interpretation of the data and writing of the report. CA, HB and WW assisted with the writing of the report. The Raine study was conceptualised and designed by the Raine Investigators group and ongoing data collection, study design and data stewardship is undertaken by the Raine Executive (Perth Western Australia). 
Funding This work was supported by a grant to Professor Paul Leeson from the British Heart Foundation (FS/11/65/28865).

Competing interests None declared.

Provenance and peer review Not commissioned; externally peer reviewed.

Data sharing statement No additional data are available.

Open Access This is an Open Access article distributed in accordance with the Creative Commons Attribution Non Commercial (CC BY-NC 4.0) license, which permits others to distribute, remix, adapt, build upon this work noncommercially, and license their derivative works on different terms, provided the original work is properly cited and the use is non-commercial. See: http:// creativecommons.org/licenses/by-nc/4.0/

\section{REFERENCES}

1. Kajantie E, Eriksson JG, Osmond C, et al. Pre-eclampsia is associated with increased risk of stroke in the adult offspring: the Helsinki birth cohort study. Stroke 2009;40:1176-80.

2. Davis EF, Lazdam M, Lewandowski AJ, et al. Cardiovascular risk factors in children and young adults born to preeclamptic pregnancies: a systematic review. Pediatrics 2012;129:e1552-61.

3. Lazdam M, de la Horra A, Diesch J, et al. Unique blood pressure characteristics in mother and offspring after early onset preeclampsia. Hypertension 2012;60:1338-45.

4. Lazdam M, de la Horra A, Pitcher A, et al. Elevated blood pressure in offspring born premature to hypertensive pregnancy: is endothelial dysfunction the underlying vascular mechanism? Hypertension 2010:56:159-65.

5. Lewandowski AJ, Augustine D, Lamata $P$, et al. Preterm heart in adult life: cardiovascular magnetic resonance reveals distinct differences in left ventricular mass, geometry and function. Circulation 2013;127:197-206.

6. Lewandowski AJ, Leeson P. Preeclampsia, prematurity and cardiovascular health in adult life. Early Hum Dev 2014;90:725-9.

7. Lewandowski AJ, Davis EF, Yu G, et al. Elevated blood pressure in preterm-born offspring associates with a distinct antiangiogenic state and microvascular abnormalities in adult life. Hypertension 2015:65:607-14.

8. Davis EF, Newton L, Lewandowski AJ, et al. Pre-eclampsia and offspring cardiovascular health: mechanistic insights from experimental studies. Clin Sci (Lond) 2012;123:53-72.

9. Lawlor DA, Macdonald-Wallis C, Fraser A, et al. Cardiovascular biomarkers and vascular function during childhood in the offspring of mothers with hypertensive disorders of pregnancy: findings from the Avon Longitudinal Study of Parents and Children. Eur Heart $J$ 2012;33:335-45.

10. Fraser A, Nelson SM, Macdonald-Wallis C, et al. Hypertensive disorders of pregnancy and cardiometabolic health in adolescent offspring. Hypertension 2013;62:614-20.

11. Mamun AA, Kinarivala MK, O'Callaghan M, et al. Does hypertensive disorder of pregnancy predict offspring blood pressure at 21 years? Evidence from a birth cohort study. J Hum Hypertens 2012;26:288-94.

12. Parkinson JR, Hyde MJ, Gale C, et al. Preterm birth and the metabolic syndrome in adult life: a systematic review and meta-analysis. Pediatrics 2013;131:e1240-63.

13. McKnight CM, Newnham JP, Stanley FJ, et al. Birth of a cohort-the first 20 years of the Raine study. Med J Aust 2012;197:608-10.

14. Hippisley-Cox J, Coupland C, Robson J. et al. Derivation, validation, and evaluation of a new QRISK model to estimate lifetime risk of cardiovascular disease: cohort study using QResearch database. BMJ 2010;341:c6624.

15. Macdonald W, Newnham J, Gurrin L. Effect of frequent prenatal ultrasound on birthweight: follow up at 1 year of age. Lancet 1996;348:482.

16. Huang RC, Mori TA, Beilin LJ. Early life programming of cardiometabolic disease in the Western Australian pregnancy cohort (Raine) study. Clin Exp Pharmacol Physiol 2012;39:973-8.

17. Huang RC, Mori TA, Burrows $S$, et al. Sex dimorphism in the relation between early adiposity and cardiometabolic risk in adolescents. $J$ Clin Endocrinol Metab 2012:97:E1014-22.
18. Ambrosini GL, Oddy WH, Huang RC, et al. Prospective associations between sugar-sweetened beverage intakes and cardiometabolic risk factors in adolescents. Am J Clin Nutr 2013;98:327-34.

19. NICE. Hypertension: clinical management of primary hypertension in adults. London: NICE, 2011.

20. NICE. Obesity: NICE guideline. London, UK: National Institute for Health and Clinical Excellence, 2006.

21. Brown MA, Lindheimer MD, de Swiet M, et al. The classification and diagnosis of the hypertensive disorders of pregnancy: statement from the International Society for the Study of Hypertension in Pregnancy (ISSHP). Hypertens Pregnancy 2001;20:ix-xiv.

22. Tenhola S, Rahiala E, Martikainen A, et al. blood pressure, serum lipids, fasting insulin, and adrenal hormones in 12-year-old children born with maternal preeclampsia. J Clin Endocrinol Metab 2003;88:1217-22.

23. Robinson MR, Scheuermann-Freestone M, Leeson $\mathrm{P}$, et al Uncomplicated obesity is associated with abnormal aortic function assessed by cardiovascular magnetic resonance. J Cardiovasc Magn Reson 2008;10:10.

24. Maximova K, O'Loughlin J, Paradis G, et al. Changes in anthropometric characteristics and blood pressure during adolescence. Epidemiology 2010;21:324-31.

25. Tenhola S, Rahiala E, Halonen $\mathrm{P}$, et al. Maternal preeclampsia predicts elevated blood pressure in 12-year-old children: evaluation by ambulatory blood pressure monitoring. Pediatr Res 2006:59:320-4.

26. Leenen FHH, Dumais $\mathrm{J}$, Mclnnis $\mathrm{NH}$, et al. Results of the Ontario survey on the prevalence and control of hypertension. CMAJ 2008;178:1441-9.

27. Henderson JJ, McWilliam OA, Newnham JP, et al. Preterm birth aetiology 2004-2008. Maternal factors associated with three phenotypes: spontaneous preterm labour, preterm pre-labour rupture of membranes and medically indicated preterm birth. J Matern Fetal Neonatal Med 2012;25:642-7.

28. March of Dimes, PMNCH, Save the Children, WHO. Born too soon: the global action report on preterm birth. In: Howson CP, Kinney MV Lawn JE, eds. Geneva: World Health Organization, 2012.

29. Wilcox AJ, Weinberg CR, Basso O. On the pitfalls of adjusting for gestational age at birth. Am J Epidemiol 2011;174:1062-8.

30. Lewandowski AJ, Bradlow WM, Augustine D, et al. Right ventricular systolic dysfunction in young adults born preterm. Circulation 2013;128:713-20.

31. Kelly BA, Lewandowski AJ, Worton SA, et al. Antenatal glucocorticoid exposure and long-term alterations in aortic function and glucose metabolism. Pediatrics 2012;129:e1282-90.

32. Lewandowski AJ, Lazdam M, Davis E, et al. Short-term exposure to exogenous lipids in premature infants and long-term changes in aortic and cardiac function. Arterioscler Thromb Vasc Biol 2011;31:2125-35.

33. Williams PJ, Broughton Pipkin F. The genetics of pre-eclampsia and other hypertensive disorders of pregnancy. Best Pract Res Clin Obstet Gynaecol 2011;25:405-17.

34. Jayet P-Y, Rimoldi SF, Stuber T, et al. Pulmonary and systemic vascular dysfunction in young offspring of mothers with preeclampsia. Circulation 2010;122:488-94.

35. Odom LN, Taylor HS. Environmental induction of the fetal epigenome. Expert Rev Obstet Gynecol 2010;5:657-64.

36. Yuen RKC, Penaherrera MS, von Dadelszen $P$, et al. DNA methylation profiling of human placentas reveals promoter hypomethylation of multiple genes in early-onset preeclampsia. Eur J Hum Genet 2010;18:1006-12.

37. Stergiou GS, Alamara CV, Salgami EV, et al. Reproducibility of home and ambulatory blood pressure in children and adolescents. Blood Press Monit 2005;10:143-7.

38. Hansen ML, Gunn PW, Kaelber DC. UNderdiagnosis of hypertension in children and adolescents. JAMA 2007;298:874-9.

39. Goddings A-L, James DR, Hargreaves DS. Distinct patterns of health engagement in adolescents and young adults: implications for health services. Lancet 2012;380:S41.

40. Bellamy L, Casas J-P, Hingorani AD, et al. Pre-eclampsia and risk of cardiovascular disease and cancer in later life: systematic review and meta-analysis. BMJ 2007;335:974.

41. Othman AS, Othman NI, Rosman A, et al. Central and periphera blood pressure profile of young offspring with hypertensive and normotensive parents. J Hypertens 2012;30:1552-5. 